\title{
Walter Benjamin, Gershom Scholem, Quelques façons de lire le texte coranique
}

Limoges, Lambert-Lucas, 2009, 260 p.

\section{(2) OpenEdition \\ Journals}

\section{Édition électronique}

URL : http://journals.openedition.org/assr/23448

DOI : $10.4000 /$ assr.23448

ISSN : $1777-5825$

\section{Éditeur}

Éditions de l'EHESS

\section{Édition imprimée}

Date de publication : 31 décembre 2011

Pagination : 114

ISBN : 9782713223273

ISSN : 0335-5985

\section{Référence électronique}

"Walter Benjamin, Gershom Scholem, Quelques façons de lire le texte coranique », Archives de sciences sociales des religions [En ligne], 156 | octobre-décembre 2011, document 156-19, mis en ligne le 14 février 2012, consulté le 21 septembre 2020. URL : http://journals.openedition.org/assr/23448 ; DOI : https://doi.org/10.4000/assr.23448 


\section{Walter Benjamin, Gershom Scholem, Quelques façons de lire le texte coranique}

Limoges, Lambert-Lucas, 2009, 260 p.

\section{RÉFÉRENCE}

Walter Benjamin,Gershom Scholem, Théologie et utopie. Correspondance 1933-1940, Postface de Stéphane Mosès, trad. de l'allemand par Didier Renault et Pierre Rusch. Paris, Éditions de l'Éclat, 2010, 333 p.

Djamel Kouloughli, Mustapha BEN TAїBI, Quelques façons de lire le texte coranique, Limoges, Lambert-Lucas, 2009, $260 \mathrm{p}$.

1 Cet ouvrage est à l'origine une thèse de linguistique soutenue sous la direction du Professeur Frédéric François, qui d'ailleurs en fait une préface lucide, modeste, et qui résume les enjeux de l'entreprise en une question: peut-on appliquer les méthodes élaborées pour expliciter le fonctionnement des textes littéraires à des textes réputés rapporter la parole divine ? Le préfacier répond « qu'il le faut bien, puisque ces textes s'adressent à des hommes et à leurs façons de comprendre ». C'est donc à cette tentative que s'attache cet ouvrage en mobilisant les ressources conjuguées des acquis des théories de l'énonciation, du dialogisme bakhtinien et de l'analyse littéraire pour éclairer certains aspects du texte coranique.

2 L'ouvrage est organisé en trois parties. La première, intitulée «Le Coran comme objet de lecture et comme objet d'étude », introduit des concepts fondamentaux comme celui de texte, de séquence et de stratégie discursive. La deuxième intitulée «L'énonciation, dimension constitutive du discours coranique » met en œuvre, dans l'approche du texte coranique, les concepts d'énonciation, de locuteur, d'allocutaire, de destinataire, d'auteur, et analyse à chaque fois les distinctions, parfois subtiles, toujours nécessaires, que ces concepts permettent d'établir face au texte coranique. La troisième partie, intitulée "Effets de textes, effets de sens", approfondit l'analyse à travers 
l'introduction de notions relatives aux genres discursifs. L'auteur y discute de la distinction entre discours et récit, description et narration, sens propre et sens figuré, ce qui lui permet de problématiser sur des bases conceptuelles claires la délicate question du statut de l'imaginaire dans le Coran, et plus généralement du problème fondamental de la dimension de l'interprétation. L'auteur aborde aussi, dans le cours de sa discussion l'articulation complexe des discours direct et indirect, et présente, pour éclairer son propos, une analyse de plusieurs dialogues représentatifs. Il consacre, dans ses développements, une attention particulière à la sourate 7 , la sūrat al-'árăf, l'une des sourates « longues » de la période mecquoise.

3 Les outils conceptuels que l'auteur introduit pour étayer son approche sont tous utiles, et en général bien maîtrisés. On peut cependant faire à ce travail certaines critiques et regretter certains manques. Ainsi, lorsque l'auteur décide (p. 102) «d'ouvrir (...) une parenthèse sur l'organisation verbale de l'arabe ", il se lance manifestement dans une entreprise pour laquelle il n'est pas suffisamment équipé, et sa "parenthèse », loin d'éclairer son propos, y introduit de nombreuses confusions, particulièrement lorsqu'il pense pouvoir conclure (note de bas de p. 103) ; «Donc à fáala dans le système verbal arabe correspondent les formes composées du français et à yaf alu les formes simples » (sic). Quand on sait qu'au passé simple français correspond systématiquement une forme fáala en arabe, on se dit qu'il aurait mieux valu pour la crédibilité de l'auteur chez les arabisants ne pas s'aventurer sur ce terrain glissant.

4 Toujours concernant la langue arabe, on regrette que les transcriptions de passages $d u$ Coran (par exemple p. 126) utilisent un système fantaisiste et sans rigueur, alors que le système en usage chez les arabisants n'est plus l'apanage de spécialistes. On peut aussi regretter que l'auteur, qui prône l'utilisation des outils de la linguistique pour approcher le texte coranique, semble ignorer complètement que longtemps avant lui, dans la tradition linguistique arabe, des auteurs comme Al-Ğurğānī (m. 1078)dans son Dalā'il al-'iğğz, ou al-Zamakšarī (m. 1144) dans son Kaššăf, avaient ouvert la voie à ce type d'approche, et que bien des points qu'il discute dans son travail l'ont déjà été par ces auteurs, avec les outils théoriques dont ils disposaient, et dont beaucoup présentent une étonnante proximité avec ceux que la linguistique moderne a forgés.

Enfin, il est dommage que l'auteur se soit contenté de la seule traduction française du Coran de Denise Masson, quelles que soient ses qualités. Une approche qui aurait confronté quelques traductions françaises récentes (il y en a bien eu une dizaine ce dernier demi-siècle) et repéré certains points stratégiques sur lesquels elles divergent (par exemple la manière de rendre en français certains fa'ala, justement) aurait certainement enrichi sa réflexion.

Il reste que l'ouvrage de M. Ben Taïbi est une entreprise courageuse en ces temps où les anathèmes sont aisément jetés à la tête de quiconque prétend poser un regard neuf sur les Grands Textes de la tradition. Il appartiendra à chaque lecteur d'apprécier dans quelle mesure l'ouvrage atteint les objectifs qu'il s'est assignés. 